\title{
A TeCHNical Study AND ANALYSis ON FuZZY SIMILARITY BASED MODELS FOR TEXT Classification
}

\author{
Shalini Puri ${ }^{1}$ and Sona Kaushik ${ }^{2}$ \\ ${ }^{1}$ M. Tech. Student, Birla Institute of Technology, Mesra, Ranchi, Jharkhand, India \\ eng.shalinipuri30@gmail.com \\ ${ }^{2}$ M. Tech. Student, Birla Institute of Technology, Mesra, Ranchi, Jharkhand, India \\ sonakaushik22@gmail.com
}

\begin{abstract}
In this new and current era of technology, advancements and techniques, efficient and effective text document classification is becoming a challenging and highly required area to capably categorize text documents into mutually exclusive categories. Fuzzy similarity provides a way to find the similarity of features among various documents. In this paper, a technical review on various fuzzy similarity based models is given. These models are discussed and compared to frame out their use and necessity. A tour of different methodologies is provided which is based upon fuzzy similarity related concerns. It shows that how text and web documents are categorized efficiently into different categories. Various experimental results of these models are also discussed. The technical comparisons among each model's parameters are shown in the form of a 3-D chart. Such study and technical review provide a strong base of research work done on fuzzy similarity based text document categorization.
\end{abstract}

\section{KEYWORDS}

Text Classification, Feature Extraction, Feature Clustering, Data Dimensionality, Fuzzy Similarity, Fuzzy Association, Membership Function, Data Sets

\section{INTRODUCTION}

Text categorization [1] [2] is an upcoming and vital field in today's world which is most importantly required and demanded to efficiently categorize various text documents into different categories. Artificial Intelligence [3] - [5] provides many learning methods and paradigms to represent, interpret and acquire domain knowledge to help other documents in learning. Such categorization must produce the accurate and correct results with high performance. Due to the huge data size and complexity, data dimensionality reduction has also been a primary concern. Great levels of efforts have been put in this direction, so that the major problem of curse of dimensionality can be reduced.

Text documents clusterization [1] [2] [6] has been paid good attention. Many models and techniques have been developed for clustering. The clustering techniques can be applied to the web documents also. In this way, they can be categorized into their major and respective categories of business, stock, sports, cricket, movie, news and many more. Therefore, the unsupervised learning paradigm [6] is used to make the document clusters. It does not include any prior information and knowledge, that' why it requires complex text processing techniques.

Nowadays, text classification [7] - [16] [19] - [28] is gaining more attention and focus for text categorization activities [17] [18] even at the overhead of increased cost. Research is also being done for the fuzzy association, signature, c-means, algorithms and methods for categorization tasks. Text classification with fuzzy logic base provides a better forum to sufficiently categorize

DOI : $10.5121 /$ ijdkp.2012.2201 
the text and web documents. It also results in justified solutions with reduced efforts. When it is combined with the feature clustering technique, it highly improves the representation of features. It further improves the storage performance and decreases the risks of feature ambiguity. Therefore, text classification techniques provide prior information and classification knowledge, so that classifiers can be made learnable to further categorize text and web documents. Many researchers are doing well in this area. Some of the applications in this field are, text classification system SECTCS (Smart English and Chinese Text Classification System) [8], segmenting handwritten text [9], nonlinear dimensionality reduction techniques [10] [11], complex linguistic features in context - sensitive text classification techniques [7] [12], cyber terrorism investigation [13], spam filtering [14] [15], topic spotting, email routing, language guessing, and many more. Text Classification and clustering are two opposite extremes with regard to the extent of human supervision they require. Real-life applications are considered somewhere in between, because unlabeled data is easy to collect but labelling data is more helpful.

As these techniques pay the attention on the accurate and correct categorization; they focus on the text pre-processing and document similarity analysis as well. During text pre-processing, the set of words are extracted to find out the concepts as features or words by using Verb-Argument Structures [6] or Pseudo Thesaurus [20]. In some research areas, bag-of-words [25] is found from the text documents. This word set is a huge collection of words that needs to be reduced further by using feature clustering [25] [28] methods. The resultant small collection of words is analyzed for the document similarity [16] [22] - [28]. If some of the documents are found similar, they are categorized into one. Many fuzzy similarity based models and algorithms have been introduced with the very nature of its membership functions [22] - [28], fuzzy association [24] [28], fuzzy C-means, production rules [19] [27]. Text classification using fuzzy based similarity is an essential task in today's categorization forum and typically, getting a great attention in various related application fields and areas. Nowadays, such concerns have been the part of many applications and related studies. Some of the applications are related to the learning evaluation [28] and education learning styles [19].

Section 2 discusses the key points and related aspects of theoretical background of fuzzy similarity based models and techniques. Section 3 discusses a technical comparative study on different fuzzy similarity based models. It discusses and shows various methods and their methodologies in detail. In section 4, an analytical discussion on the experimental results is given. Various results and their important concerns are discussed and shown with respect to different parameters. Finally, section 5 concludes the paper.

\section{THEORETICAL BACKGROUND}

Over the last decades, fuzzy similarity based text document classification has got attention very much and considered as an important research area. Different techniques, models and ways are searched to design a best categorization system. Such field is not only used in the small level organizations, industries and corporate, but also covers a vast community all around the world. The new techniques, their collaboration and research always open a new paradigm towards the advancements.

Current research studies show that fuzzy logic and its area of concerns provide efficient base for text categorization, dimensionality reduction, feature selection and extraction, and similarity analyzer related issues. Fuzzy logic is considered as a branch of logic especially designed for representing knowledge and human reasoning in such a way that it is amenable to processing by a computer [3]. The major concepts of fuzzy logic are fuzzy sets, linguistic variable, possibility distributions, and fuzzy if - then rules. Fuzziness or Degree of Uncertainty pertains to the uncertainty associated with a system, i.e., the fact that nothing can be predicted with exact 
precision. Practically, the values of variables are not always precise; rather approximate values are more likely to be known. The vagueness can adequately be handled using fuzzy set theory. This theory provides a strict mathematical framework using which vague conceptual phenomena can be studied rigorously. It is also called the property of language [3] - [5]. Its main source is the imprecision involved in defining and using symbols. It is a property of models, computational procedures, and languages. Hence, a fuzzy set is a collection of distinct elements with a varying degree of relevance or inclusion.

\subsection{Feature Clustering}

The concept of feature clustering [10] [11] [22] - [24] enhances the provision of text dimension criticality solution. It is an efficient way to compress the collected feature sets more, so that the resultant data can be handled and used properly without any loss. These clusters are represented either by the term of maximum frequency in a group (or cluster) [22] [24] or can be found by self constructing feature clustering algorithm [23]. Feature clustering is also done with the use of the pseudo-thesaurus by identifying each term [6] as noun, pronoun, adverb, adjective, delimiters etc. Researchers have shown that it helps to reduce the high dimensional data into smaller one adequately.

\subsection{Fuzzy Association}

Fuzzy sets pay an important and vital role in text categorization. They are widely recognized as many real world relations are intrinsically fuzzy. Fuzzy association [24] [28] is used to discover important associations between different sets of attribute values. A fuzzy association rule $\mathrm{A} \Rightarrow$ $\square \mathrm{C}$ is very strong if both $\mathrm{A} \Rightarrow \mathrm{C}$ and $\square \mathrm{C} \Rightarrow \square \mathrm{A}$ are strong.

\subsection{Fuzzy Production Rules}

The novel method of rule-base construction and a rule weighting mechanism [19] [27] can result in a rule-base containing rules of different lengths, which is much more useful when dealing with high dimensional data sets.

\subsection{Fuzzy Clustering and C-Means}

In fuzzy clustering [28], each point has a degree of belonging to clusters, as in fuzzy logic, rather than belonging completely to one cluster. Thus, points on the edge of a cluster may be in the cluster to a lesser degree than points in the centre of cluster.

\subsection{Fuzzy Signatures}

Fuzzy signatures [26] are used in those applications and key areas which require the handling of complex structured data and interdependent feature problems. They can also used in special concerns where data is missing. So, this depicts many areas where objects with very complex and sometimes interdependent features are to be classified along with the evaluation of similarities and dissimilarities. This leads a complex decision model hard to construct effectively. Due to the very nature of fuzzy signatures of flexibility, it can be used for many text mining tasks, with the benefit of the hierarchical structuring; therefore, the text document classification models can be constructed [26].

\section{A Technical Comparative Study on Different Fuzzy SIMILARITY BASED MODELS}

Research work on fuzzy similarity based models and techniques has taken a new turn for the text classification tasks with the involvement of different key concerns related to the fuzzy logic and sets. Therefore, these techniques provide better ways and solutions for categorization. 


\subsection{A Comparative Description on Various Proposed Techniques}

The comparative detailed description on different techniques is described in table 1. It defines the challenges and problems occurred in each model, which are the related key issues. These models focus on different concerned issues and necessities of the text classification area. The similarity technique shows the efficient similarity criteria used in the model.

Table 1. A Comparative Study among Various Fuzzy Similarity Based Models and Techniques.

\begin{tabular}{|c|c|c|c|c|}
\hline $\begin{array}{l}\mathbf{S} \\
\mathbf{N}\end{array}$ & $\begin{array}{l}\text { Ref. } \\
\text { No. }\end{array}$ & Problem Focused & Designed Aim & $\begin{array}{l}\text { Similarity } \\
\text { Technique }\end{array}$ \\
\hline 1. & {$[22]$} & $\begin{array}{l}\text { Comparative study } \\
\text { of web-pages } \\
\text { classification for } \\
\text { Arabic Web-pages. }\end{array}$ & $\begin{array}{l}\text { Arabic Web page classification } \\
\text { using fuzzy similarity approach } \\
\text { of fuzzy term relation category. }\end{array}$ & $\begin{array}{l}\text { Fuzzy based } \\
\text { similarity approach. }\end{array}$ \\
\hline 2. & {$[23]$} & $\begin{array}{l}\text { Challenge of } \\
\text { ambiguity in } \\
\text { systems to handle } \\
\text { natural language. } \\
\text { - Issue of linguistic } \\
\text { ambiguities found in } \\
\text { text classification. }\end{array}$ & $\begin{array}{l}\text { Proposed a text categorizer using } \\
\text { Fuzzy Similarity methodology } \\
\text { and Agglomerative Hierarchical } \\
\text { Algorithms; Clique and Star, } \\
\text { without needing to determine the } \\
\text { number of initial categories. }\end{array}$ & $\begin{array}{l}\text { Text categorizer of } \\
\text { two algorithms } \\
\text { based on fuzzy } \\
\text { similarity } \\
\text { method. based }\end{array}$ \\
\hline 3. & {$[24]$} & $\begin{array}{l}\text { The same word or } \\
\text { vocabulary to } \\
\text { describe different } \\
\text { entities creates } \\
\text { ambiguity, } \\
\text { especially in the } \\
\text { Web environment } \\
\text { for large user } \\
\text { population is large. }\end{array}$ & $\begin{array}{l}\text { A method of automatically } \\
\text { classifying Web documents into } \\
\text { a set of categories using the } \\
\text { fuzzy association concept is } \\
\text { proposed to avoid the ambiguity } \\
\text { in word usage. }\end{array}$ & $\begin{array}{l}\text { Similarity of distinct } \\
\text { keywords r of } \\
\text { documents with the } \\
\text { categories. }\end{array}$ \\
\hline 4. & {$[25]$} & $\begin{array}{l}\text { Need of a powerful } \\
\text { method to reduce } \\
\text { the dimensionality } \\
\text { of feature vectors } \\
\text { for } \quad \text { text } \\
\text { classification. }\end{array}$ & $\begin{array}{l}\text { Proposed a fuzzy similarity- } \\
\text { based self-constructing } \\
\text { algorithm for feature clustering. } \\
\text {-Highly reduces the data } \\
\text { dimensionality as each cluster, } \\
\text { formed automatically, is } \\
\text { characterized by a membership } \\
\text { function with statistical mean } \\
\text { and deviation. It chooses one } \\
\text { extracted feature for each } \\
\text { cluster. }\end{array}$ & $\begin{array}{l}\text { Grouping of words } \\
\text { in the feature vector } \\
\text { of a document set } \\
\text { into fuzzy clusters, } \\
\text { based on similarity } \\
\text { test. }\end{array}$ \\
\hline 5. & {$[26]$} & $\begin{array}{l}\text { Problem to identify } \\
\text { the representation } \\
\text { units as tokens using } \\
\text { bag-of-words } \\
\text { methods in some } \\
\text { Asian Languages of } \\
\text { non-segmented text. }\end{array}$ & $\begin{array}{l}\text { Proposed the fuzzy signature } \\
\text { based solution using frequent } \\
\text { max substring mining because } \\
\text { of its language independency } \\
\text { and favorable speed and store } \\
\text { requirements. } \\
\text { - Deals with cases to handle } \\
\text { complex structure data, to } \\
\text { handle overlapping information, }\end{array}$ & $\begin{array}{l}\text { Extracting index } \\
\text { terms and use of a } \\
\text { Super Substring } \\
\text { definition to reduce } \\
\text { the number of index } \\
\text { terms. } \\
\text { - Reduction in terms } \\
\text { of finding out no } \\
\text { super substring }\end{array}$ \\
\hline
\end{tabular}




\begin{tabular}{|c|c|c|c|c|}
\hline & & & $\begin{array}{l}\text { to include evolving information } \\
\text { easily and to handle missing } \\
\text { information. }\end{array}$ & $\begin{array}{l}\text { pattern among index } \\
\text { terms. }\end{array}$ \\
\hline 6. & {$[27]$} & $\begin{array}{l}\text { Challenge in high } \\
\text { dimensional systems } \\
\text { to generate every } \\
\text { possible rule with } \\
\text { respect to all } \\
\text { antecedent } \\
\text { combinations. } \\
\end{array}$ & $\begin{array}{l}\text { Proposed a method for rule } \\
\text { generation, which can result in a } \\
\text { rule-base containing rules of } \\
\text { different lengths. }\end{array}$ & $\begin{array}{l}\text { Production rule } \\
\text { matching. }\end{array}$ \\
\hline \multicolumn{5}{|c|}{ Learning Evaluation } \\
\hline 7. & {$[28]$} & $\begin{array}{l}\text { Issues of expressing } \\
\text { the fuzziness and } \\
\text { uncertainty of } \\
\text { domain knowledge } \\
\text { and the semantic } \\
\text { retrieval of fuzzy } \\
\text { information. }\end{array}$ & $\begin{array}{l}\text { - Produced an extended fuzzy } \\
\text { ontology model/ } \\
\text { - Proposed a semantic query } \\
\text { expansion technology to } \\
\text { implement semantic information } \\
\text { query based on the property } \\
\text { values and the relationships of } \\
\text { fuzzy concepts. }\end{array}$ & $\begin{array}{lr}\text { Semantic } & \text { similarity } \\
\text { and } & \text { semantic } \\
\text { correlation in fuzzy } \\
\text { concept analysis. }\end{array}$ \\
\hline
\end{tabular}

\subsection{A Tour on Different Methodologies and Procedures}

Various methodologies and procedures are depicted in table 2. These methodologies are shown in steps. [22], [23], [24], and [25] show that text documents or web documents are considered for text classification which use a predefined set of classes initially in the training phase. In [22], [23] and [24], the text is pre-processed and cleaned to extract all important features. In [25], a bag of words is used and processed to get the word patterns. Next, the fuzzy similarity techniques are applied as shown in table 1. Finally, text is classified using the classifier. Different methods have implemented different procedures to categorize the text.

The use of fuzzy signature for the text classification of the non-segmented text [26] shows that how the non-segmentable text can be segmented and classified. In [27], a rule based weighting technique is used to efficiently perform the data mining tasks. The learning evaluation using the extended fuzzy ontology model [28] is provided for learning techniques based classification. The given models have the key concern of the feature set reduction and improve the overall system performance.

Table 2. Proposed Methodologies of Various Models and Techniques.

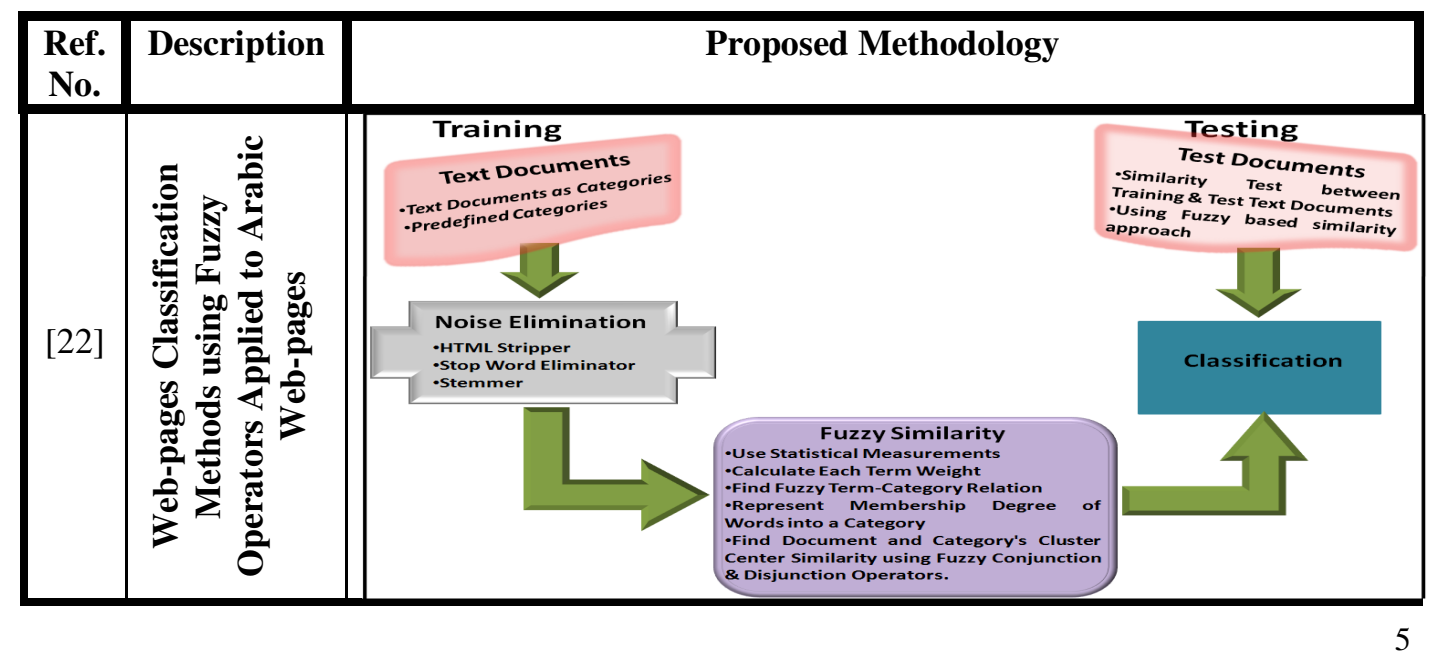


International Journal of Data Mining \& Knowledge Management Process (IJDKP) Vol.2, No.2, March 2012

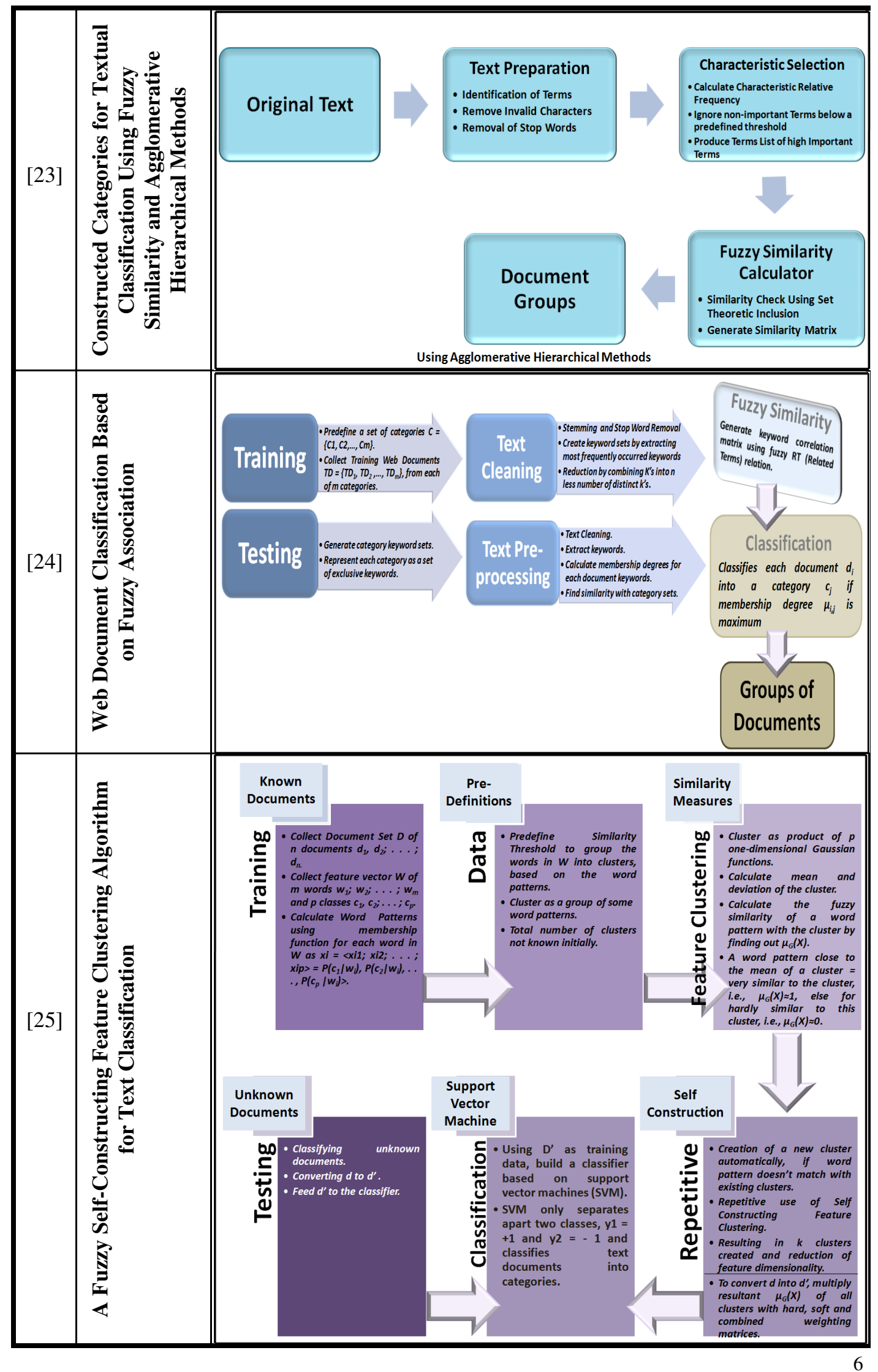


International Journal of Data Mining \& Knowledge Management Process (IJDKP) Vol.2, No.2, March 2012

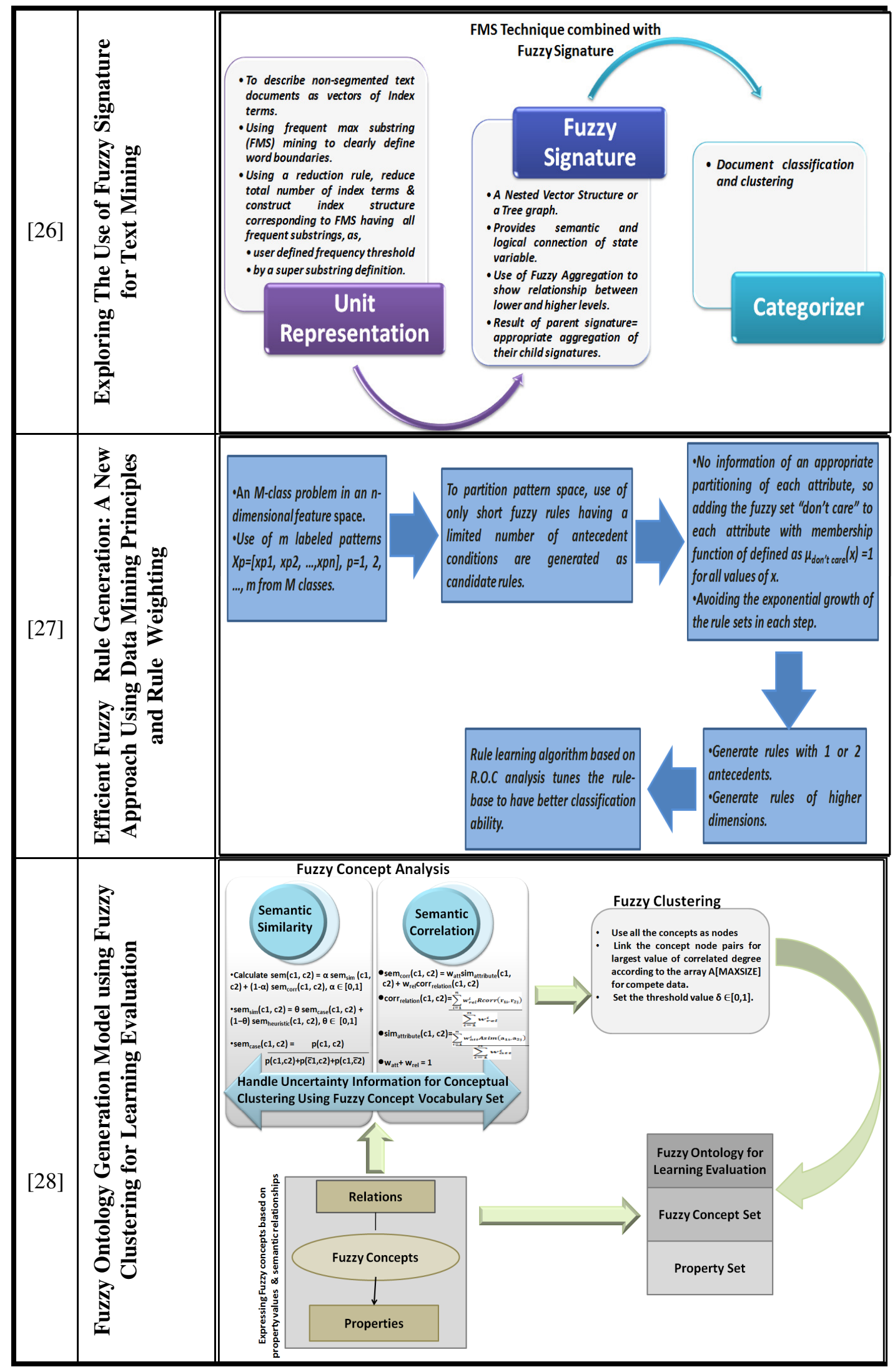




\section{An AnAlytical DiscuSsion On EXPERIMENTAL RESUltS}

Various fuzzy similarity models for text classification have been successfully implemented. Their experimental results are shown and discussed in detail. The accuracy and performance parameters are evaluated and checked to see the utility of the methods and the current state - of - the - art.

\subsection{Experimental Results: Data Sets and Evaluation}

The experiments and results found for various models are discussed in table 3 . It shows total data sets used, total number of categories generated and the results found for each technique. The data sets are considered from the newsgroups, newspapers, different text document pages of corpus, portals, Reuters, and repositories. Different categories are built initially in the training phase. These techniques have used documents from small corpus to large corpora, and considered few categories to many categories.

Experimental results found show that how the corresponding proposed technique is comparatively better than others. Some results have shown the performance and accuracy improvements, speed increase, reduced storage and many advantageous parameters.

Table 3. An Analysis Showing Different Experimental Results on Document Classification.

\begin{tabular}{|c|c|c|c|}
\hline $\begin{array}{l}\text { Ref. } \\
\text { No. }\end{array}$ & Data Set & Categories & Results Found \\
\hline \multirow{3}{*}[22]{} & 50 Arabic Pages & \multirow{3}{*}{$\begin{array}{l}\text { 10 Categories: Autobiography } \\
\text { (Auto), Children's Stories } \\
\text { (Child), Economics (Eco), } \\
\text { Health and Medicine (Hlth), } \\
\text { Interviews (Intrv), Religion } \\
\text { (Rlg), Science (Scnc), Short } \\
\text { Stories (Short), Sociology } \\
\text { (Socio), Tourist and Travel } \\
\text { (Trst). }\end{array}$} & \multirow{3}{*}{$\begin{array}{l}\text { Accuracy Performance } \\
\text { Achieved in the Decreasing } \\
\text { order: Einstein bounded, } \\
\text { Algebraic, } \\
\text { Hamacher, MinMax. ScFuzzy, }\end{array}$} \\
\hline & $\begin{array}{l}5 \text { Pages per } \\
\text { Categories }\end{array}$ & & \\
\hline & $\begin{array}{l}6 \text { Measures: } \\
\text { Einstein, } \\
\text { Algebraic, } \\
\text { Hamacher, } \\
\text { MinMax, Special } \\
\text { case fuzzy and } \\
\text { Bounded } \\
\text { Difference. }\end{array}$ & & \\
\hline \multirow{4}{*}[23]{} & 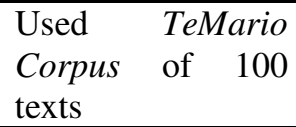 & \multirow{3}{*}{$\begin{array}{l}\text { Data Used for Simulation: } \\
\text { From Origin and Title } \\
5 \text { categories, each of } 20 \text { texts: } \\
\text { from two Brazilian } \\
\text { newspapers, Folha de São } \\
\text { Paulo (Special, World, and } \\
\text { Opinion) and Jornal do Brasil } \\
\text { (Politics and International). }\end{array}$} & \multirow{3}{*}{$\begin{array}{l}\text { - A slight advantage of Clique } \\
\text { algorithm over Star, but with } \\
\text { greater number of groupings. } \\
\text { - Similar results of both for } \\
\text { relationship rule. } \\
\text { - Excellent results for fuzzy } \\
\text { similarity (set theoretic } \\
\text { inclusion). } \\
\text { - Efficient technique of } \\
\text { relative frequency in the } \\
\text { characteristics selection } \\
\text { phase. }\end{array}$} \\
\hline & \multirow{2}{*}{\begin{tabular}{l|l} 
Summaries & Source \\
Manual & Texts \\
Summaries & With \\
Marked & Title \\
Manual & With \\
Summaries & out Title \\
Ideal & With \\
Automatic & Origin \\
Extracts & and Title
\end{tabular}} & & \\
\hline & & & \\
\hline & \begin{tabular}{|lr}
\multicolumn{3}{|c}{ Data sets collected } \\
from & Web \\
portals: & Yahoo! \\
and & Open \\
Directory & Project \\
$($ ODP $)$ & \\
\end{tabular} & $\begin{array}{l}\text { Yahoo! Portal 12 Categories } \\
\text { Arts \& Humanities (art), } \\
\text { Business \& Economy (bus), } \\
\text { Computers \& Internet (com), } \\
\text { Education } \\
\text { Entertainment }\end{array}$ & $\begin{array}{l}\text { - Achieved higher accuracy in } \\
\text { Fuzzy approach compared to } \\
\text { the vector space model with } \\
\text { Cosine coefficient. } \\
\text { - Total Accuracy }\end{array}$ \\
\hline
\end{tabular}




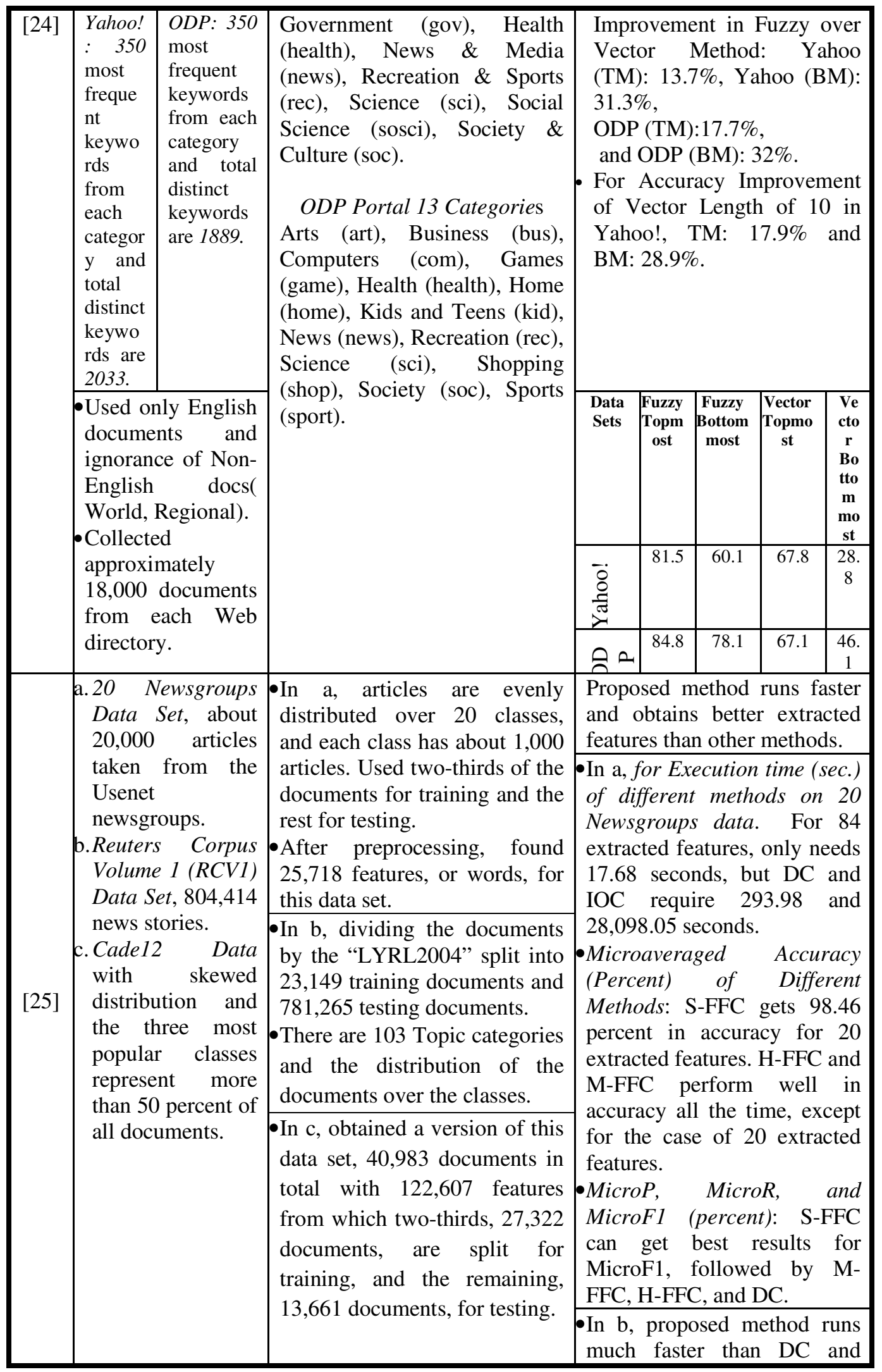




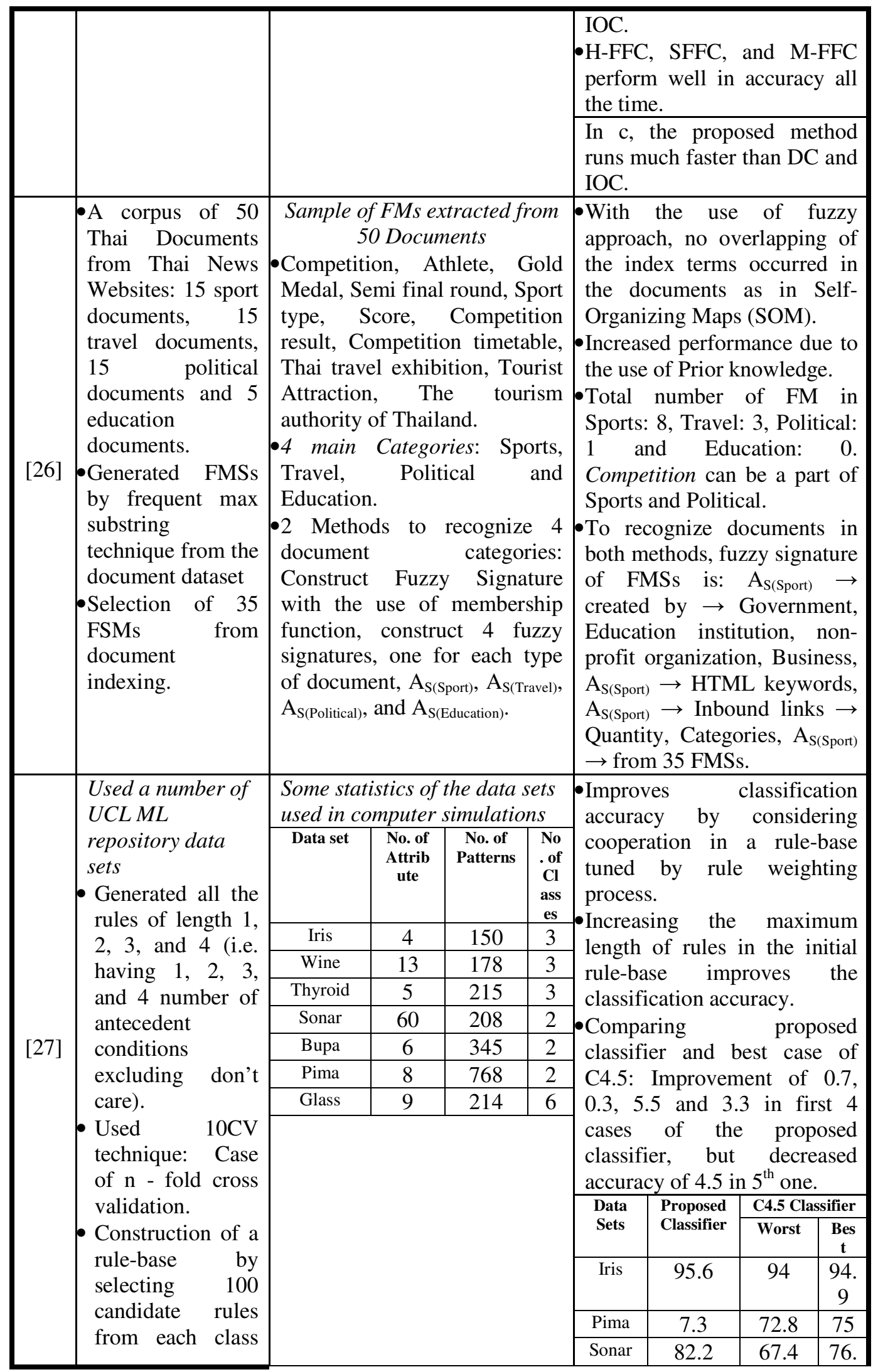


International Journal of Data Mining \& Knowledge Management Process (IJDKP) Vol.2, No.2, March 2012

\begin{tabular}{|c|c|c|c|c|c|c|}
\hline & \multirow{3}{*}{$\begin{array}{l}\text { using the } \\
\text { selection metric. }\end{array}$} & & & & & 7 \\
\hline & & & Wine & 97.7 & 92.2 & $\begin{array}{c}94 . \\
4\end{array}$ \\
\hline & & & Glass & 68.2 & 68.8 & $\begin{array}{c}72 . \\
7\end{array}$ \\
\hline [28] & $\begin{array}{l}\text { Learning } \\
\text { Evaluation for } \\
\text { Teaching Field } \\
\text { Consider Entity } \\
\text { concept "student" } \\
\text { a. Property Set: } \\
\text { \{learning attitude, } \\
\text { learning ability, } \\
\text { text scores,...\} } \\
\text { b.Property Value } \\
\text { set: } \\
\text { - learning attitude } \\
\text { ( very good, } \\
\text { basic good, bad, } \\
\text { very bad, ...). } \\
\text { - learning ability } \\
\text { (most strong, } \\
\text { very strong, } \\
\text { strong, general } \\
\text { weak, weak, } \\
\text { great weak, ...). } \\
\text { - text scores } \\
\text { (extremely high, } \\
\text { high, medium, } \\
\text { slight low, low, } \\
\text {...). }\end{array}$ & 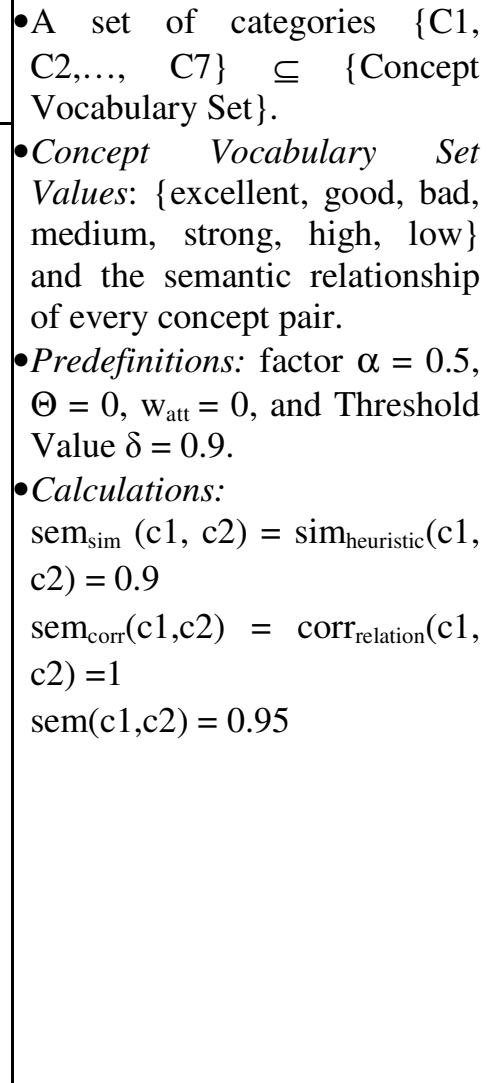 & $\begin{array}{l}\cdot \text { Produc } \\
\text { Conne } \\
28 \text { Di } \\
\text { matrix } \\
\text { result } \\
\text { duplic } \\
\text { total n } \\
\text { is } 7 \text { tin } \\
\text { is } 3 \text { tin } \\
\text { is } 2 \text { tin } \\
- \text { Graph } \\
\text { among } \\
\text { C5, } \\
\text { C2 } \rightarrow C \\
\cdot \text { Perfor } \\
\text { based } \\
- \text { Detern } \\
\text { the inf } \\
\text { the exa } \\
- \text { Shows } \\
\text { extend } \\
\text { model } \\
\text { Ontolo }\end{array}$ & 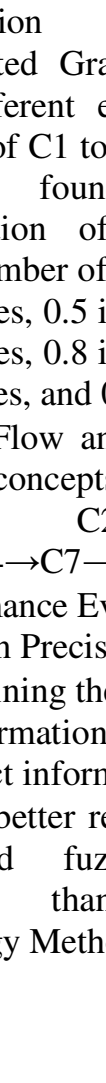 & $\begin{array}{l}\quad \text { Co } \\
\text { with } \\
\text { tries in } \\
7 \text {, whe } \\
\text { entries } \\
\text { is } 8 \text { tin } \\
4 \text { times } \\
3 \text { times } \\
9 \text { is } 1 \text { ti } \\
\text { connec } \\
\text { are, } \mathrm{C} 1 \\
3 \text {. } \\
\text { luation } \\
\text { n. } \\
\text { elevan } \\
\text { nd obta } \\
\text { tion. } \\
\text { ults fou } \\
\text { ont } \\
\text { Cla } \\
\text { l. }\end{array}$ & $\begin{array}{l}\text { cept } \\
\text { total } \\
7 * 7 \\
\text { the } \\
\text { hout } \\
\text { as, } \\
\text { es, } 1 \\
0.95 \\
0.35 \\
\text { e. } \\
\text { ions } \\
\text { C6, } \\
\text { and } \\
\\
\text { ing } \\
\text { ing } \\
\text { ing } \\
\text { sical }\end{array}$ \\
\hline
\end{tabular}

\subsection{Various Experimental Results on the Models}

The experimental results of various models show their good performance and accuracy concerns. In figure 1, these models are discussed and their studies, results, comparisons of experimental results are shown. The bars in chart are individual and independent in their identity. These results are not compared with each other; they only provide their data, and respective details.

Fuzzy term-category relation [22] is shown by manipulating membership degree for the training data and the degree value for a test web page. Six measures are used and compared where the best performance was achieved by Einstein. Accuracy performance of these algorithms in the decreasing order is shown in figure 1. With this, the training data collected from different sources is normalized and pre-processed and then these measures are applied on it. Text categorization based on the Agglomerative Hierarchical Methodology [23] with the use of fuzzy logic. As for the use of the star and clique algorithms used in the agglomerative hierarchical methodology to identify the groups of text by specifying some type of relationship rule, they obtained similar results, but the clique algorithm showed a slight advantage when compared to the star, despite having created greater number of groupings. In figure 1, star and clique algorithms are compared for the parameters, number of categories, group of 10 or more texts and categories of only one text. Clique shows better results than star. 
To automatically classify the web documents using the fuzzy association concept [24], the relationship is captured among different index terms in documents. This approach is compared with vector space model approach and it shows improved results than VSM. To see the effect of different keyword selections for category vectors, 2 different alternatives are there: Selecting from the most frequently occurred keywords(topmost) and selecting from the least frequently occurred keywords (bottommost) with varying vector lengths have been used. Yahoo! And ODP portals are compared with each other for the topmost and bottommost cases as shown in figure 1. In [25], a small part of the total result is shown in chart. It is only shown for a subsection of the 20 newsgroups.

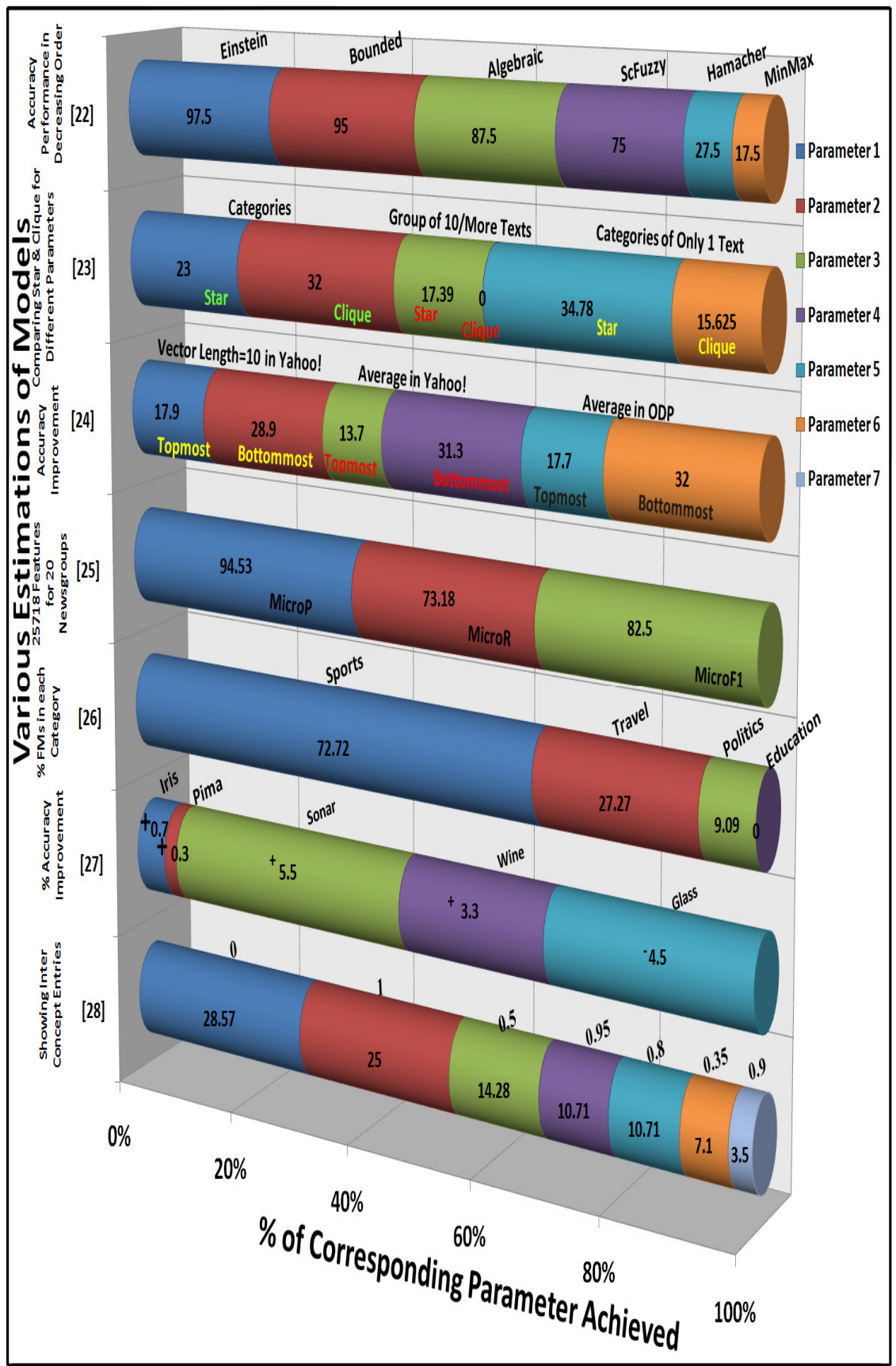

Figure 1. Various Models, their Parametric analysis with Experimental Results 
[26] discusses the simple category distribution in each of the 4 type of documents of sample data. In [27] and [28], the parameters are calculated as given in the table 3. In [27], Iris showed better results over others. In [28], to make the information semantization and to improve the accuracy of information retrieval, it adopted a fuzzy concept semantic analysis for clustering to generate learning evaluation ontology. It achieves high information retrieval and improves efficiency as compared to fuzzy ontology.

\section{Conclusions}

In this paper, different fuzzy similarity related algorithms and methodologies are discussed in detail. Different researches depict good results with the underlying techniques, mechanisms and methodologies. The experimental results provide good fuzzy based text classification with high accuracy. These models focus on new kinds of different classification issues and techniques. Therefore, these research studies and their survey contribute in providing the information about advanced fuzzy classification, related models and techniques.

The analytical review provides a simple summary of the sources in an organizational pattern and combines both summary and synthesis to give a new interpretation of old material. Therefore, it aims to review the critical points of current knowledge of research work including substantive findings as well as theoretical and methodological contributions. Additionally, their experimental results and their parametric data are sufficiently described and compared independently. Such comparative studied and technical analysis charts provide a strong base to understand the use of fuzzy and its related concerns. Various experimental results have proven themselves good for the models and techniques. The utility of fuzzy logic and its areas give a good effect on text mining and text classification. Therefore, fuzzy similarity is used in many application areas and fields all around the world for categorization.

\section{ACKNOWLEDGEMENTS}

We would like to give our special thanks to Asst. Prof. Pankaj Gupta, Dept. of Computer Science, Birla Institute of Technology, Noida Extension Centre, Uttar Pradesh, India and Dr. Vikas Saxena, Dept. of Computer Science, Jaypee Institute of Information Technology, Noida, Uttar Pradesh, India for their help and guidance.

\section{REFERENCES}

[1] Jiawei Han, \& Miche Line Kamber, (2006) Data Mining: Concepts and Techniques, 2nd ed., Elsevier.

[2] Margaret H. Dunham, Data Mining: Introductory and Advanced Topics, Pearson Education.

[3] N. P. Padhy, (2009) Artificial Intelligence and Intelligent Systems, 5th ed., Oxford University Press.

[4] Eliane Rich, Kevin Knight \& Shivashankar B Nair, (2010) Artificial Intelligence, 3rd ed., Mc Graw Hill.

[5] Stuart Russell, \& Peter Norvig, Artificial Intelligence: A Modern Approach, Pearson Education.

[6] Shady Shehata, Fakhri Karray, \& Mohamed S. Kamel, (2010) "An Efficient Concept-Based Mining Model for Enhancing Text Clustering", IEEE Transactions on Knowledge and Data Engineering, Vol. 22, No. 10, pp. 1360 - 1371.

[7] Y.V. Haribhakta \& Parag Kulkarni, (2011) "Learning Context for Text Categorization", International Journal of Data Mining \& Knowledge Management Process (IJDKP), Vol. 1, No. 6, pp. $15-23$.

[8] Mingyu Lu, Keyun Hul, Yi Wu, Yuchang Lu, \& Lizhu Zhoul, (2002) "SECTCS: Towards improving VSM and Naive Bayesian Classifier", IEEE International Conference on Systems, Man and Cybernetics, Vol. 5. 
International Journal of Data Mining \& Knowledge Management Process (IJDKP) Vol.2, No.2, March 2012

[9] Yi Sun, Timothy S. Butler, Alex Shafarenko, Rod Adams, Martin Loomes, \& Neil Davey, (2004) "Segmenting Handwritten Text Using Supervised Classification Techniques", Proc. of IEEE International Joint Conference on Neural Networks, Vol. 1, pp. 657 - 662.

[10] Lukui Shi, Jun Zhang, Enhai Liu, \& Pilian He, (2007) "Text Classification based on Nonlinear Dimensionality, Reduction Techniques and Support Vector Machines", Third IEEE International Conference on Natural Computation, Vol. 1, pp. 674 - 677.

[11] Fouzi Harrag, Eyas El - Qawasmah, \& Abdul Malik S. - Salman, (2010) "Comparing Dimension Reduction Techniques for Arabic Text Classification using BPNN Algorithm", First IEEE International Conference on Integrated Intelligent Computing (ICIIC), pp. 6 - 11.

[12] Alex K. S. Wong, John W. T. Lee, \& Daniel S. Yeung, (2005) "Using Complex Linguistic Features In Context - Sensitive Text Classification Techniques", Proc. of the Fourth IEEE International Conference on Machine Learning and Cybernetics, Vol. 5, pp. 3183 - 3188.

[13] David Allister Simanjuntak, Heru Purnomo Ipung, Charles Lim, \& Anto Satriyo Nugroho, (2010) "Text Classification Techniques Used To Facilitate Cyber Terrorism Investigation", Second IEEE International Conference on Advances in Computing, Control, and Telecommunication Technologies (ACT), pp. 198 - 200.

[14] Upasana, \& S. Chakravarty, (2010) “A Survey of Text Classification Techniques for E - mail Filtering", Second IEEE International Conference on Machine Learning and Computing (ICMLC), pp. $32-36$.

[15] M. Fong, (2008) "Spam or Ham", Introduction to Artificial Intelligence Project.

[16] B. S. Harish, S. Manjunath \& D. S. Guru, (2012) "Text Document Classification: An Approach Based On Indexing", International Journal of Data Mining \& Knowledge Management Process (IJDKP), Vol. 2, No. 1, pp. 43 - 62.

[17] K. Srinivasa Rao \& V. Chiranjeevi, (2011) "Distortion Based Algorithms For Privacy Preserving Frequent Item Set Mining", International Journal of Data Mining \& Knowledge Management Process (IJDKP), Vol. 1, No. 4, pp. $15-27$.

[18] J. Malar Vizhi \& T. Bhuvaneswari, (2012) "Data Quality Measurement on Categorical Data Using Genetic Algorithm”, International Journal of Data Mining \& Knowledge Management Process (IJDKP), Vol. 2, No. 1, pp. $33-42$.

[19] Rahmah Mokhtar, Siti Norul Huda Sheikh Abdullah, \& Nor Azan Mat Zin, (2011) "Classifying Modality Learning Styles based on Production Fuzzy Rules", IEEE International Conference on Pattern Analysis and Intelligent Robotics (ICPAIR), Vol. 1, pp. 154 - 159.

[20] Surya Sumpeno, Mochamad Hariadi, \& Mauridhi Hery Purnomo, (2011) "Facial Emotional Expressions of Life-like Character Based on Text Classifier and Fuzzy Logic", IAENG International Journal of Computer Science.

[21] Giuseppe Fenza, Vincenzo Loia, \& Sabrina Senatore, (2008) "Concept Mining of Semantic Web Services By Means Of Extended Fuzzy Formal Concept Analysis (FFCA)”, IEEE International Conference on Systems, Man, Cybernetics (SMC), pp. 240- 245.

[22] Ahmad T. Al-Taani, \& Noor Aldeen K. Al - Awad, (2005) "A Comparative Study of Web-pages Classification Methods using Fuzzy Operators applied to Arabic Web-pages”, World Academy of Science, Engineering and Technology, pp. 33- 35.

[23] Marcus Vinicius, C. Guelpeli, Ana Cristina, \& Bicharra Garcia, (2007) "An Analysis of Constructed Categories for Textual Classification using Fuzzy Similarity and Agglomerative Hierarchical Methods", Third International IEEE Conference Signal-Image Technologies and Internet-Based System (SITIS), pp. 92 - 99.

[24] Choochart Haruechaiyasak, Mei-Ling Shyu, Shu-Ching Chen, \& Xiuqi Li, (2002) "Web Document Classification Based on Fuzzy Association", Proc. of Annual International Computer Software and Applications Conference (COMPSAC), pp. 487 - 492. 
[25] Jung-Yi Jiang, Ren-Jia Liou, \& Shie-Jue Lee, (2011) “A Fuzzy Self-Constructing Feature Clustering Algorithm for Text Classification", IEEE Transactions On Knowledge And Data Engineering, Vol. 23, No. 3, pp. 335 - 349.

[26] Kok Wai Wong, Todsanai Chumwatana, \& Domonkos Tikk, (2010) "Exploring the Use of Fuzzy Signature for Text Mining", IEEE International Conference on Fuzzy Systems (FUZZ), pp. $1-5$.

[27] O. Dehzangi, M. J. Zolghadri, S. Taheri \& S.M. Fakhrahmad, (2007) "Efficient Fuzzy Rule Generation: A New Approach Using Data Mining Principles and Rule Weighting", Fourth IEEE International Conference on Fuzzy Systems and Knowledge Discovery (FSKD), Vol. 2, pp. 134 139.

[28] Qing Yang, Wei Chen, \& Bin Wen, (2009) "Fuzzy Ontology Generation Model using Fuzzy Clustering for Learning Evaluation”, IEEE International Conference on Granular Computing $(G R C)$, pp. $682-685$.

\section{Authors}

Shalini Puri received the B. E. Degree in Computer Science from Mody College of Engineering and Technology, Sikar, Rajasthan, India in 2002. She is pursuing M. Tech. in Computer Science at Birla Institute of Technology, Mesra, Ranchi, Jkarkhand, India. She is currently working as an Assistant Professor in a reputed engineering college in India. She has published many international journals and presented papers in IEEE conferences. Her research areas include Artificial Intelligence, Data Mining, Soft Computing, Graph Theory, and Software Engineering.

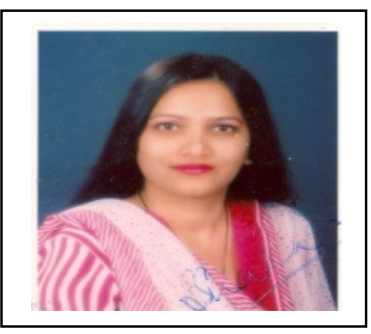

Sona Kaushik belongs to National Capital Region, New Delhi, India. She received the B.Tech. Degree in Information Technology in 2007. She is currently working as a System Engineer in a reputed IT Organisation and pursuing Masters in Technology from Birla Institute of Technology, Mesra, Ranchi, India. She has published many international journals and presented papers in IEEE conferences. Her research interests are in information security, network security, security engineering and cryptography.

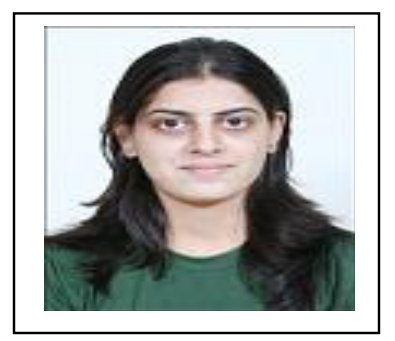

